\title{
Esthetic management of diastema closure using metal ceramic crowns: A case report
}

\author{
Alyami Jaber* \\ General Dental Practitioner at Asser Specialist Dental Center,Kingdom Saudi Arabia
}

\begin{abstract}
Closing a diastema or a gap is an esthetically challenge for many clinicians.Many treatment option were used such as orthodontic treatment, resin-based composite restorations, and veneers or crowns.

This case report highlights an esthetic closing of a gap spacing between maxillay canine and lateral incisor teeth using metal ceramic crowns to provide an acceptable esthetic outcome.
\end{abstract}

\section{Introduction}

Diastema or more commonly known as tooth gaps can occur for several reasons, from natural to behavioral. The causes of diastema are the discrepaacy between the size of the teeth and that the jaw, unerupted teeth, oral habits (such as tongue thrusting and thumb sucking), periodontitis, mesiodens, oversized labial frenum and missing teeth. Treatment is mainly for esthetic and psychological reasons, rather than functional ones [1].

Various multidisciplinary treatment by means of direct and/or indirect restorative treatment such as bonding composite approach, fixed or removable orthodontic appliances to simply close the spaces. Ideally, orthodontic treatment must be accomplished to give proper space relationships and good occlusion but in some cases this is not possible and we need the help of the restorative treatment.

\section{Case report}

A 45 year old female patient presented to the department of fixed prosthodontics at the dental clinic with chief complaint of spacing between maxillary right canine and lateral teeth. She was displeased with her smile and seeked for aesthetic, pleasing and natural appearing like life smile.

The clinical examination and history revealed that the patient was within normal upon extra-oral examination. On intra-oral examination showed that oral hygiene was satisfactory and the patient presented with sound periodontal conditions. Dental examination revealed defective old metal ceramic crowns (margin gaps )cemented on maxillary right first and second premolar and caries on mandibular teeth and a distal caries on the maxillary right canine (Large Class IV). The measure of interdental spacing between maxillary lateral incisor and canine using a Vernier Caliper (Aerospace Digital Vernier Caliper, India) revealed $(\sim 5 \mathrm{~mm})[2]$.

Before moving forward with any treatment plan. The patient was given all the options of Closing the diastema. Furthermore, due to prolonged treatment and aesthetic issues related to these appliances, patient did not give her consent to these treatment modalities. The space was planned to be managed with metal ceramic crowns. The decision was to carry out 4 metal ceramic crows on second and first premolars, canine and lateral taking account to close the gap between lateral and canine. The gap was somewhat managed by increasing the width of lateral incisor and canine (Figures 1 and 2).

After clinical examination, photographs (Figure 3), a mask was performed directly in the mouth by means of acrylic resin to allow closing the spacing between the canine and the lateral incisor and allow to obtain patient opinion and she agreed with the new change in her teeth dimension. Removing the old crowns was performed by using sectioning with diamond burs to cut through ceramic and fissure carbide bur to cut through the metal. Sectioning was decided to avoid damaging the remaining tooth structure which could happen likely to the use a crown remover and a great care should also be taken during sectioning. The shared preparation principles in the anterior and posteriors regions for all systems (i.e., single-unit and FPD abutment) include an incisal/occlusal reduction of $1.5 \mathrm{~mm}$ to $2 \mathrm{~mm}$ [3].

These are the minimal amounts of reduction that are acceptable. Increasing the amount of incisal reduction in the anterior region to $2 \mathrm{~mm}$ gives the dental technician more room to develop the esthetics the distal caries on the canine was restored by a composite dual cure [4].

The temporary crowns were performed by resin acryl thanks to an index, as an external surface form ,performed directly in the mouth, using the old cemented crowns and the mask , as tissue surface form (Figure 4) [5].

The impression was made with polyvinylsiloxane by putty-wash technique after removing retraction cords (\#000 and \#001, Ultradent) used inorder to ensure gingival displacement and sent to the lab. After

${ }^{\star}$ Correspondence to: Jaber Sadän Hamad Alyami Asser, Specialist Dental Center, Kingdom Saudi Arabia, Tel: +966544444950; E-mail: Dr.jabersa@hotmail.com

Key words: pacing,esthetic,metal-ceramic,closure

Received: August 23, 2018; Accepted: August 29, 2018; Published: August 31, 2018 


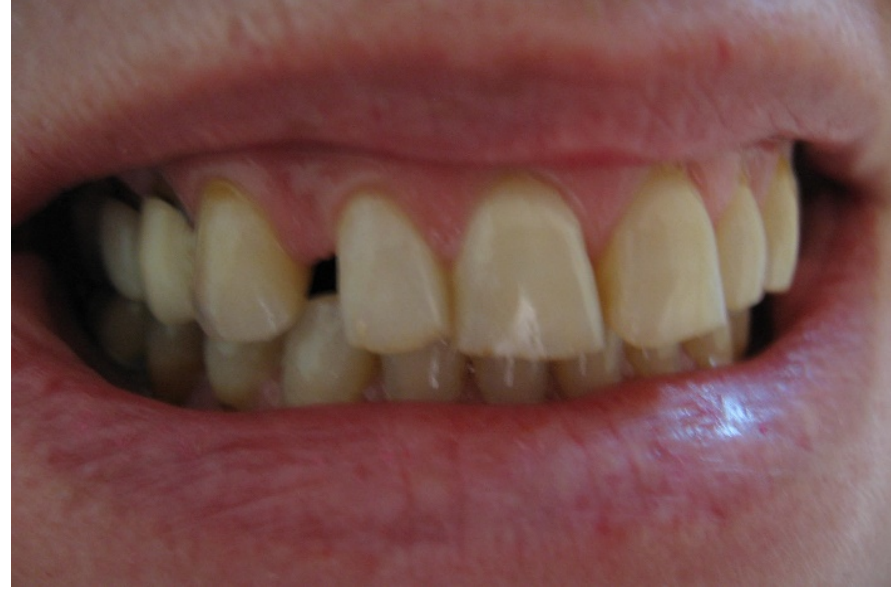

Figure 1. Pre-operative frontal view showing a gap between maxillary lateral incisor and canine $(\sim 5 \mathrm{~mm})$

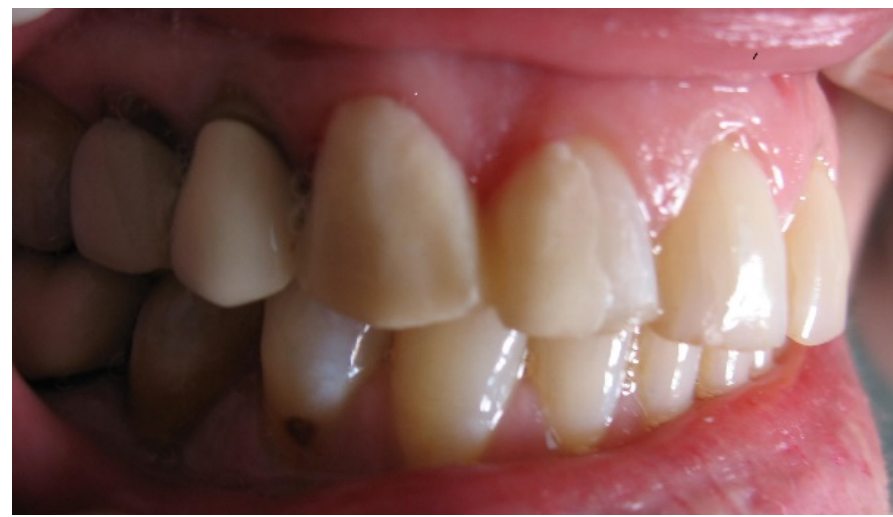

Figure 2. A mask was performed directly in the mouth by means of acrylic resin

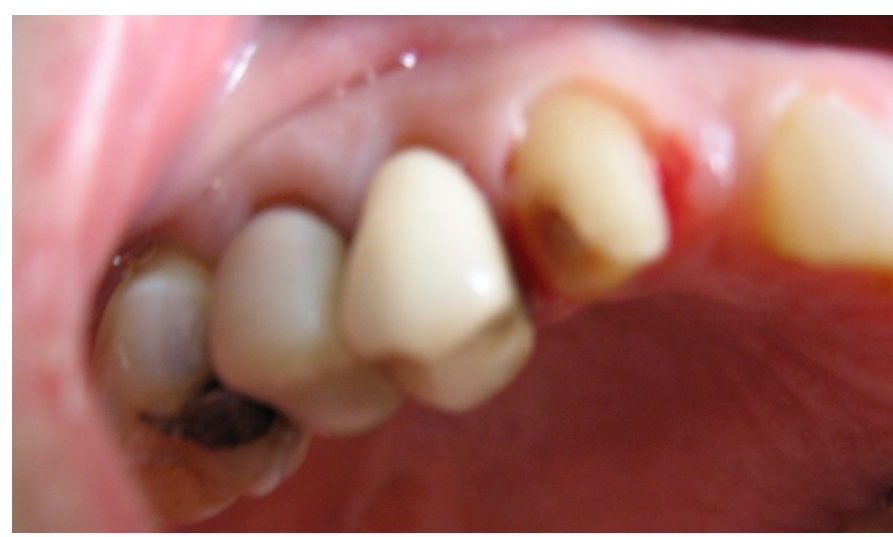

Figure 3. Preparation of canine and lateral incisor

occlusal registration, metal frameworks were tried in to confirm fit, insertion retention, marginal integrity, and mostly the space left for cosmetic ceramic. After shade selection of maxillary teeth using Vita 3D master,the bisque (Figure 5) was checked to evaluate marginal fit, esthetics, shade, and proximal contacts. Furthermore,the centric and eccentric occlusion were assessed [6].

Note the crowns on the premolars were unit and separated, whereas the crowns on canine and lateral incisor were obviously splinted. After glazing in the lab, in the clinic the metal ceramic crowns were tried again to verify final esthetic integration mostly related to the shade and cemented using glass monomer cement (Figure 6).

\section{Discussion}

Esthetics is adversely affected by diastemas [7]. Esthetic treatment of diastema closure is one of the biggest challenges practitioners face to inesthetic dentistry. Digital Smile Design is usefull to see what we can perform during our treatment and is a great tool to guide us to during the dental plan. The restorative closure of diastema can be achieved by using any of the techniques mentioned; direct composite,compsite veneers, indirect composite veneers, porcelain laminate veneers, all ceramic crowns, metal ceramic crowns [2].

Orthodontic closing diastema is indicated for all type of diastema.It is a very conservative option but it is time -consuming and financially

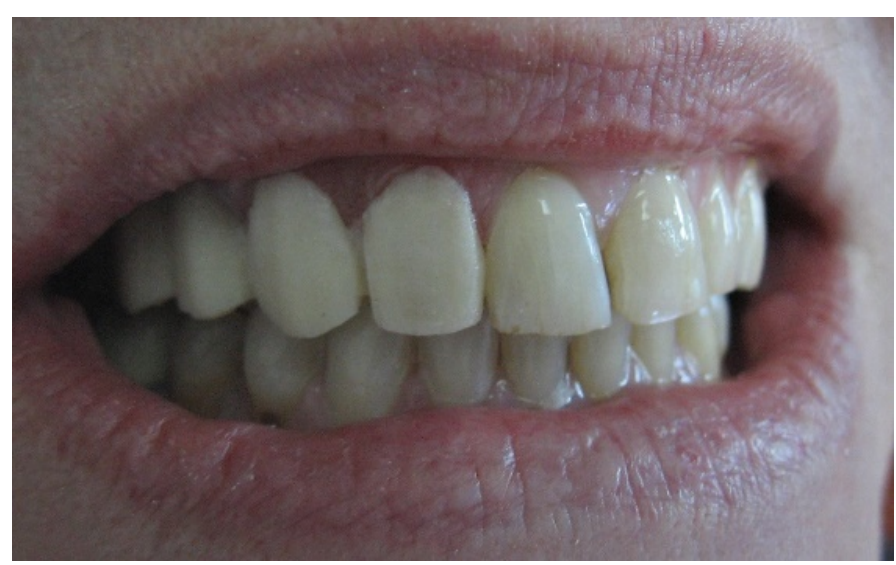

Figure 4. Interim crowns

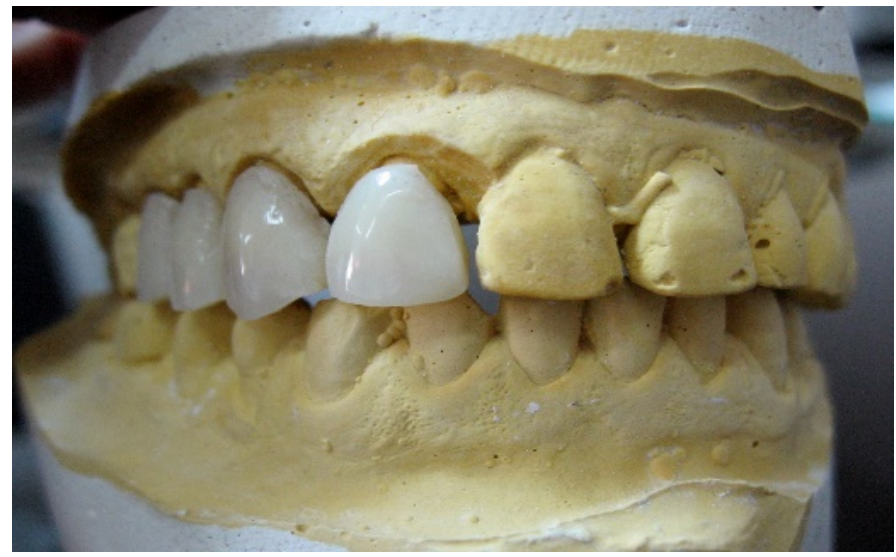

Figure 5. Metal ceramic crowns (bisque state) on working cast

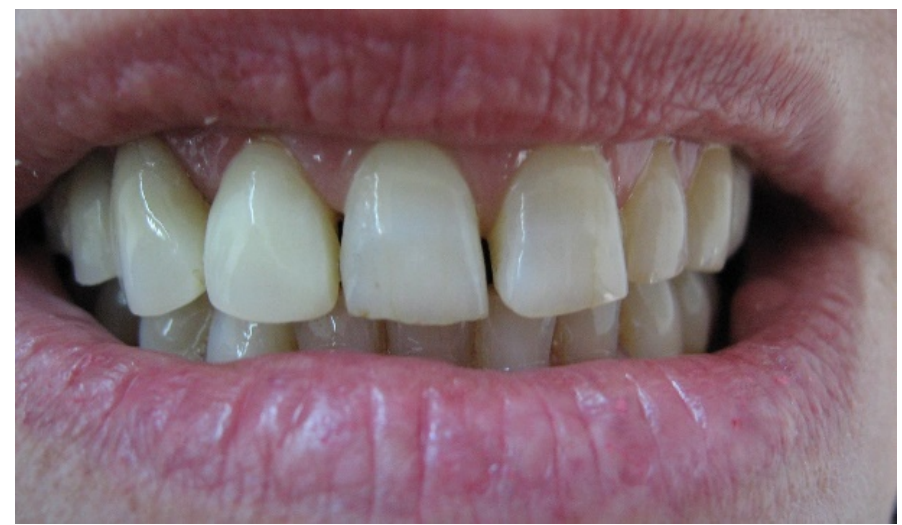

Figure 6. Final cementation with optimal esthetic outcome 
demanding. Diastema based on tooth-size discrepancy is most amenable to restorative and prosthodontic solutions. Smaller diastema can be closed with microfilled and hybrid resins if the diastema is about $1-1.5 \mathrm{~mm}$ in dimension. Success of a restorative treatment in anterior teeth depends on the esthetic integration between soft and hard tissues, direct restorative techniques can be applied to avoid "black triangles" [8]. It was explained that a black triangle results from the architecture of the bone and the distance between the contact points and the crest of the bone. When the distance from the contact point to the crest of bone was $5 \mathrm{~mm}$ or less, the papilla was present almost $100 \%[9,10]$.

Freehand direct resin composites provide an esthetic and conservative approach for closing diastema. Composite resin is easy to use, requires, single-visit procedures and bypass laboratory work which reduces cost of the treatment $[9,11]$. Excellent outcomes have been reported by numerous authors who have used resin composites for diastema closures [12-14]. It is economic but offers less wear resistance and surface staining, which makes it inferior to dental porcelain. Failures such as discoloration, marginal leakage, fracture, and debonding usually occur within 6 months of the placement of the restoration [9]. Closure of diastema less than $4 \mathrm{~mm}$ can be achieved by porcelain laminate veneers and this option provide shorter duration of treatment protocols and less number of appointments.

They can be bonded to the facial surface of anterior teeth using recent bonding agents and dual cure cements [15].

Porcelain laminate veneers have become the alternative to composite restorations, ceramic crowns and metal ceramic crowns [16]. The presented case reports justified the choice of diastema closure using metal ceramic crowns because the, spacing is quite large $(\sim 5 \mathrm{~mm})$, besides the canine was decayed and Class IV defects should not likely to be restored with veneers because, not only there was unsupported porcelain but also the lack of tooth-colored backing.Furthermore the patient can't afford all ceramic crowns.

\section{Conclusion}

The management of spacing among teeth also termed gap, diastema is really an esthetic challenge. Many treatment options are used such as orthodontie, composite restoration, veneers, and crowns. Their indications are related to the case selection (width of diastema,patient motivation) and practitioner skills.

\section{Acknowledgment}

The author wishes to thank Dr Jilani Saafi, professor in fixed prosthodonics at the Faculty of dental medicine, University of Monastir, Tunisia for the great help and support in preparing this case report.

\section{References}

1. Bernabe E, Flores-Mir C (2007) Influence of anterior occlusal characteristics on selfperceived dental appearance in young adults. Angle Orthod 77: 831-836. [Crossref]

2. Viswambaran M, Londhe SM, Vijaya Kumar (2015) Conservative and esthetic management of diastema closure using porcelain laminate veneers. Med J Armed Forces India 71: S581-S585. [Crossref]

3. Raigrodski AJ (2003) Clinical and laboratory considerations for the use of CAD/CAM Y-TZP-based restorations. Pract Proced Aesthet Dent 15: 469-476. [Crossref]

4. Saafi J, Debbabi I, Chakroun M, Nouira Z, Harzallah BH, et al. (2017) Esthetic Restoration of Two Severely Decayed Maxillary Central Incisors: A Case Report. $J$ Oral Health Dent Sci 1: 104.

5. Rosenstiel Stephen F, Land M, Fujimoto J (2006) Contemporary fixed prosthodontics. 78635 (Edn.), Mosby, Inc., an affiliate of Elsevier Inc 470-478.

6. Alalkhashab M (2018) Lithium Disilicate (E-Max Press) Based Crowns for Esthetic rehabilitation in Esthetic Zone: A Case Report. J Dental Sci 3.

7. Namdar F, Atasu M (1999) Macrodontia in association with a contrasting character microdontia. J Clin Pediatr Dent 23: 271-274. [Crossref]

8. Lacy AM (1998) Application of composite resin for single-appointment anterior and posterior diastema closure. Pract Periodont Aesthet Dent 10: 279-286. [Crossref]

9. Goyal A, Nikhil V, Singh R (2016) Diastema Closure in Anterior Teeth Using a Posterior Matrix. Case Rep Dent 2016: 2538526. [Crossref]

10. Tarnow DP, Magner AW, Fletcher P (1992) The effect of the distance from the contact point to the crest of bone on the presence or absence of the interproximal dental papilla. J Periodontol 63: 995-996. [Crossref]

11. Marcos Vargas (2013) A step-by-step approach to a diastema closure - a dual-purpose technique that manages black triangles. International Dentistry African Editions 3: 60-62.

12. Huang WJ, Creath CJ (1995) The midline diastema: a review of its etiology and treatment. Pediatr Dent 17: 171-179. [Crossref]

13. Lenhard M (2008) Closing diastemas with resin composite restorations. Eur J Esthet Dent 3: 258-268. [Crossref]

14. De Araujo EM Jr, Fortkamp S, Baratieri LN (2009) Closure of diastema and gingival recontouring using direct adhesive restorations: a case report. $J$ Esthet Restor Dent 21: 229-240. [Crossref]

15. Theodore R, Harald H, Edward S (2006) Sturdevant's Art and Science of Operative Dentistry. 5: 807-840.

16. Touati B, Miara P, Nathanson D, Martin Dunitz (1999) New York: Esthetic Dentistry and Ceramic Restorations. 161-214.

Copyright: (C2018 Jaber A. This is an open-access article distributed under the terms of the Creative Commons Attribution License, which permits unrestricted use, distribution, and reproduction in any medium, provided the original author and source are credited. 